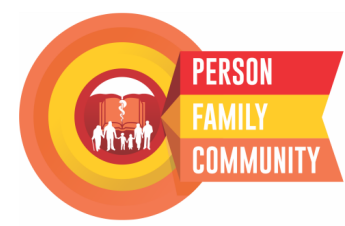

Journal Homepage:

https://jurnal.ugm.ac.id/rpcpe

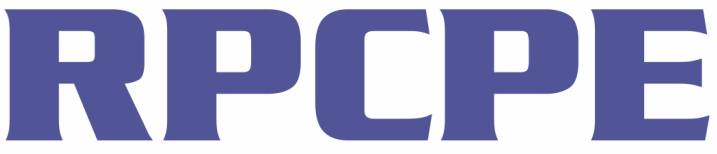

ISSN 2613-943X (print) ISSN 2620-5572 (online)

Review of Primary Care Practice and Education (Kajian Praktik dan Pendidikan Layanan Primer)

\title{
Starting Online Services at University Clinics at the Beginning of the Covid-19 Pandemic
}

Dhanasari Vidiawati Trisna ${ }^{1}$, Riri Indriyanti² ${ }^{2}$ Mora Claramita ${ }^{3}$

\author{
${ }^{1}$ Department of Community Medicine; Faculty of Medicine; University of Indonesia; Indonesia \\ ${ }^{2}$ Makara Satellite Clinic; Universitas of Indonesia; Indonesia \\ ${ }^{3}$ Departement of Medical Education and Bioethics; Faculty of Medicine, Publich Health, and Nursing; Universitas Gadjah Mada; \\ Indonesia
}

Presented at the webinar organized by the collaboration between the Indonesian Family Medicine College, the Indonesian Family Doctors Association, the Indonesian Society of Teachers in Family Medicine, the Review-Journal on Primary Care Practice and Education, and the Center for Policy Management, the Faculty of Medicine, Gadjah Mada University on April 4, 2020.

Corresponding Author:

Dhanasari Vidiawati: Department of Community Medicine, Faculty of Medicine, University of Indonesia

Email: dhanasari.vt@gmail.com

To cite this article:

Trisna DV, Indriyanti R, Claramita M. Starting Online Services at University Clinics at the Beginning of the Covid-19 Pandemic. Rev Prim Care Prac and Educ. 2020; 3(3): 2-7.

\section{INTRODUCTION}

The UI Makara Satellite Clinic (KSUI) is a university clinic that serves UI residents and the public as well as a vehicle for education and health research in primary services. It has been a BPJS Outpatient Service Clinic (KPRJ) since October 2018. It is called a Satellite Clinic because it is planned to become a satellite for university hospitals in the academic health system at the University of Indonesia. Currently, KSUI is located on the Depok campus and the Salemba campus. In its daily services at the Depok campus, KSUI provides services for doctors, dentists, nursing, pharmacy, laboratories, action rooms, and psychological counseling.

KSUI's mission is not the same as an ordinary outpatient clinic, but because KSUI is a health service facilitated by the university, KSUI has a mission to maintain the health of the academic community, and not only treat them when they fall ill. Therefore, in addition to services that respond to patients coming to the clinic, KSUI also organizes periodic health check services, facilitates Posbindu activities in the faculties and office buildings on campus, and participates in medical care at any gathering or sports activities provided on campus.

With the Covid-19 case being found in Indonesia, KSUI decided to change its service method as quickly and as firmly as possible from face-to-face services to online services, following the Chancellor's Decree to close the campus from face-to-face learning and other student activities. With the return of the UI dormitory students and the implementation of work from home (WFH) for lecturers and education staff, KSUI must provide safe services during a pandemic and can be accessed by service users without having to come to campus. Therefore, this article is a brief piece of information that has been done by KSUI when it decided that services should be carried out online. It is not easy for the officer, because it has never been done, and it is not easy for the patient.

\section{CHANGES IN THE FORM OF SERVICE FROM TIME TO TIME}

When the mass media reported the coronavirus outbreak (2019-nCov) in Wuhan City and started spreading to other cities, even to other countries, KSUI started health education through its Instagram on January 25, 2020, as an effort to increase the awareness of UI residents about a possible outbreak. will enter Indonesia. KSUI carries out services, as usual, opening services from 9 am to $9 \mathrm{pm}$. 08.00 to 08.00 , and high patient visits along with the odd semester final exam season. Every wall seen by the patient is affixed with a 'hand sanitizer' along with a 'sticker' 6 steps washing hands with a hand sanitizer.

On March 2, 2020, when it was announced that the first Indonesian patient was infected with Covid-19, panic began with UI residents by entering questions via telephone or 'Whatsapp' to health workers. KSUI then uploads information at the same time to answer questions on Instagram and on the X-banner at the clinic entitled "Am I infected with Covid-19? Stay calm and alert, consider the following explanation".

Since then, patients who come to the clinic for treatment or to ask for vitamins have greatly increased. Service hours are opened, as usual, health workers are instructed to wear medical masks while on duty at the clinic, and provide medical masks for all patients who come with complaints of fever, or runny nose, or cough.

A week after that, the government announced an increase 
in the findings of Covid-19 cases, so UI also issued a Chancellor's Circular No. 703 regarding distance education for all study programs at UI on March 13, 2020.

With the consideration that patients at KSUI who have symptoms of upper respiratory tract infection are always the highest cases every month, and the number of patients has greatly increased in the last 2 weeks, so to avoid cross-transmission that is not yet known whether they have Covid-19 or not, KSUI decided to avoid congestion. patients in the waiting room by limiting the number of services via online registration. Starting Monday, March 16,2020 , registration is carried out online, but services are still carried out face-to-face.

The narrowness of the Salemba campus clinic so does not allow for distance between patients, so starting March 17, 2020, the Salemba campus clinic services will be closed. Likewise, dental polyclinic services are at high risk of aerosol splashes during service, while equipment facilities are still inadequate to avoid aerosols, so dental poly services are eliminated.

On March 20, 2020, the next Chancellor's Circular was issued which was not only distance education for study programs, but lecturers and staff were shifted to enter $50 \%$ and at home 50\% (50:50). Starting Monday, March 23, 2020, KSUI will introduce online services for those who do not have the opportunity to provide face-to-face services with a daily quota limitation. Registration and online service which began on March 23 were preceded by a short online briefing of doctors and nurses. Arranged online and face-to-face practice schedules for doctors and nurses. Not following the SE Chancellor, KSUI employees cannot be enforced 50:50 because the service is full quota every day. In that week, KSUI also posted signs in all clinics to become physical distancing for everyone while in the clinic. Health workers use level 2 personal protective equipment (PPE), namely surgical masks, face shields, head caps, gowns, and disposable gloves, with training on how to use and how to remove them.

A week after online registration was implemented, and a few days later online services were carried out in addition to face-to-face services, KSUI had to change again because the number of Covid-19 sufferers that week had reached 1,000 patients. On March 28, 2020, KSUI announced that starting Monday, March 30, 2020, all services will be carried out online.

According to the patient's needs, laboratory and pharmacy services are open every Tuesday and Friday, so that patients who consult online can still get medicines and be examined by the laboratory as recommended by the doctor who provides online consultation. So far, online consultations have been provided for academicians and BPJS patients registered with KSUI. So that administratively this online consultation is free of charge.

\section{COMPARISON OF THE NUMBER OF SERVICES DURING A CERTAIN PERIOD}

For comparison of the same service periods, below is information on the number and type of service for 4 periods with the same number of service days, but with different situations.

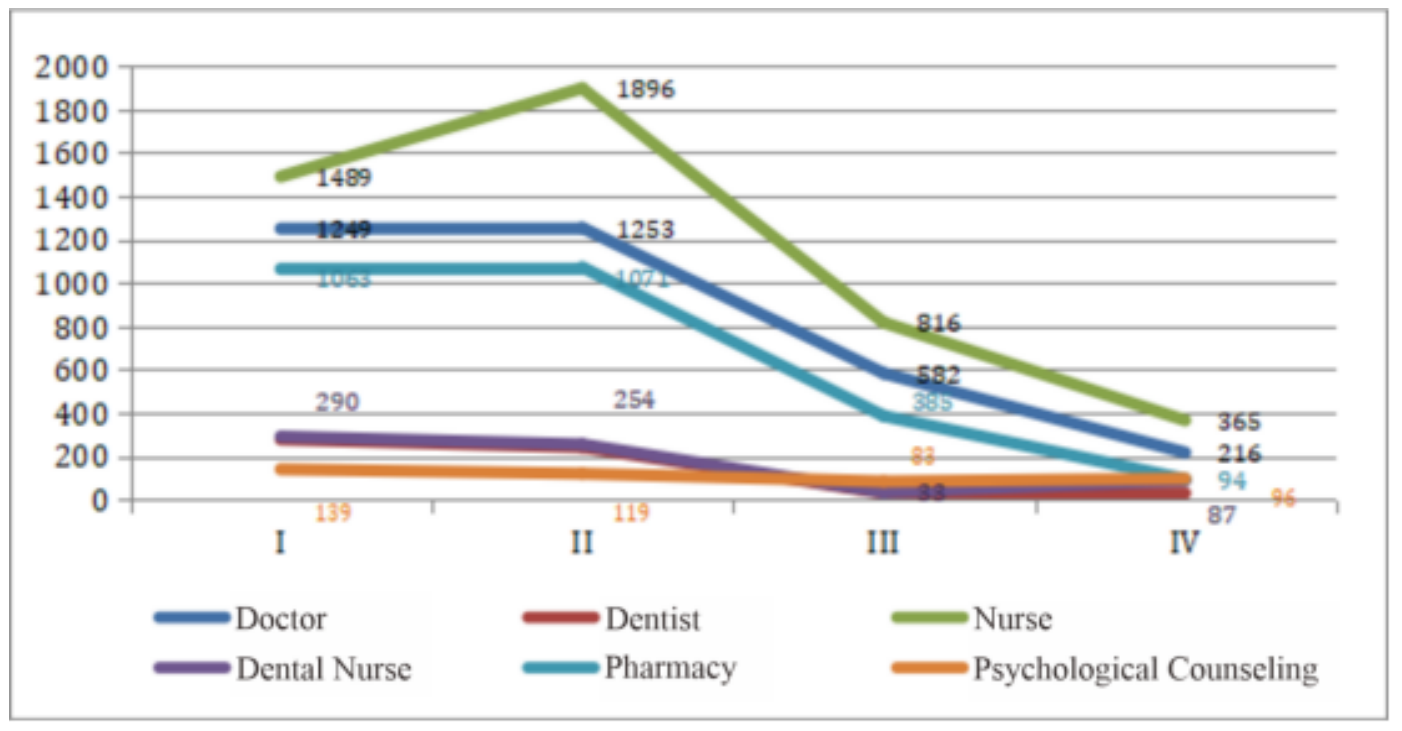

Diagram 1. Number of services per period

Period 1 is February 17-29, when Covid-19 has not been found in Indonesia, period II is March 2-14, when Covid-19 has been announced to be in Indonesia, but KSUI services are still, as usual, period III is March 16- March 29, KSUI face-to-face services with a limit on the number of queues in the form of online registration with a quota for the number of practicing doctors, and the IV period is March 30 to April 11, that is, all services are online services.
In diagram 1, it is clear that nurse patients jumped after the government announced that the first patient contracted Covid-19. Most patients want to be diagnosed with whether their symptoms are symptoms of Covid-19 or not. Nurses serve by submitting Covid-19 screening and education to calm patients. The number of patients decreased drastically when it was limited to the number of patients waiting at the clinic, which continued to decline during online services. 
It appears that psychological counseling services also experienced a drastic decline at the time of service 50:50 and increased again after the system of sharing the schedule for online counseling services was well structured.

\section{KSUI ONLINE SERVICE PROCEDURES}

It cannot be denied that the decision to quickly implement online services has been greatly assisted by the implementation of electronic medical records at KSUI since January 2019. So that all health workers have used electronic medical records from cell phones (smartphones), tablets (pad), or personal computers (PCs).
The electronic medical record system used by KSUI is eHealth by referring to online registration, as well as the distribution of doctors and nurses by the KSUI admin. Administrative officers will see registration on certain days and hours and distribute to nurses, or doctors, or other officers who are on duty that day.

The medical officer will follow up the data on their respective eHealth to be called or on the WhatsApp app, or via video call, or google hangout. All applications used are according to the convenience of patients and health workers.

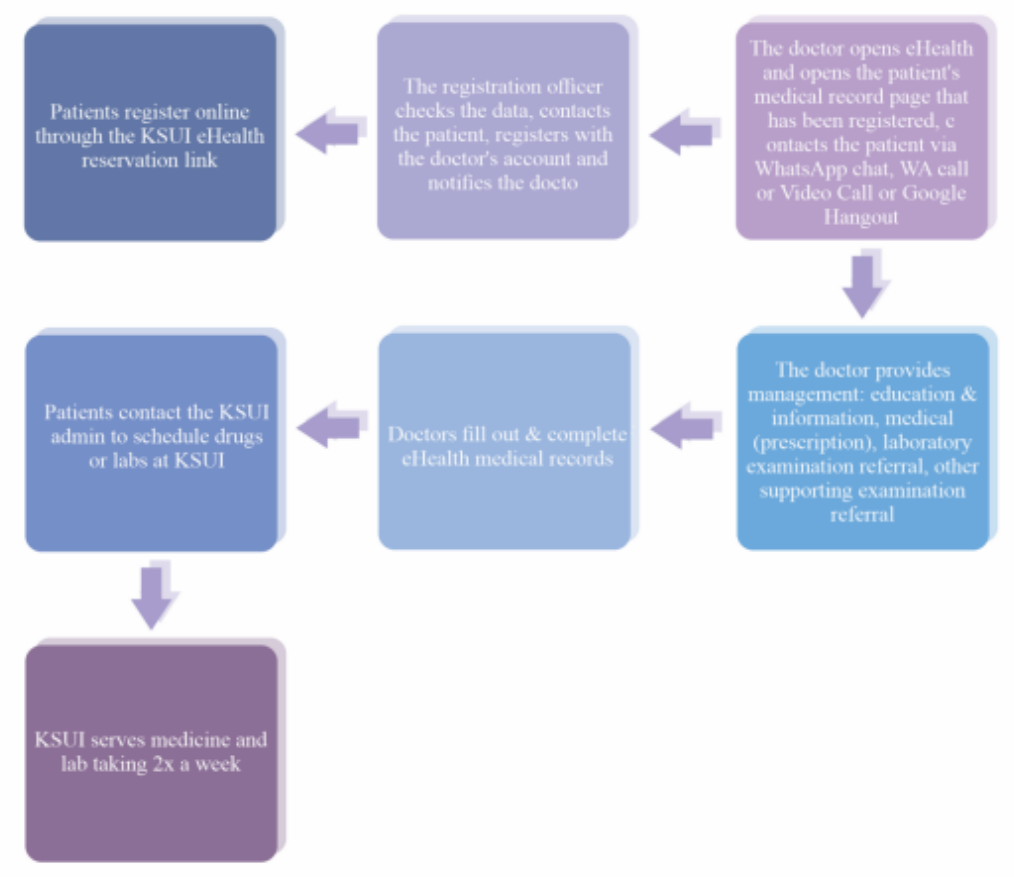

Diagram 2. The flow of online consultation services by doctors (as well as by other health workers)

The information system that adopts one telephone number at KSUI has not yet been developed, as in online medical services which are widely developed today, so health workers are forced to let their telephone numbers be known by the patients they contact. The consequence after that, patients can contact their doctor or other health workers anytime and from anywhere.

Because online services at KSUI are something that is being done for the first time, so many obstacles are experienced both from the side of electronic medical record service providers, doctors, and also patients. Some of the obstacles found were in line with what Kats SJ from Michigan University explained in 2004 that online services that had just started there were no integrated payment systems for integrated consulting services and supporting examinations, doubts about privacy, medical confidentiality, and medicolegal aspects had also become a discussion that continues to seek solutions. From the patient side, it seems that quite a lot of patients are not familiar with online communication systems, and there is a tendency that patients who "really need" medical services will not choose to use the online consultation method.

In some countries, online medical service methods have become popular beforehand, patients can even have access to enter and view their medical records registered by doctors online. At KSUI, this method cannot yet be applied. The eHealth system, which is a system for recording electronic medical records at satellite clinics, can only be accessed by medical personnel with a certain authority.

Based on research Mold F, de Lusignan S et al ${ }^{2}$ in the Journal of Personalized Medicine (2015) and de Lusignan $\mathrm{S}$, Mold F, Sheikh A, et al ${ }^{3}$ in BMJ (2014) explained that the ease with which patients can access their medical data online tends to increase their level. comfort and patient satisfaction. Even so, medical professionals are still concerned about aspects of medical confidentiality, whether it can be maintained properly. On the one hand, this is very good and beneficial for patients with chronic diseases (Prolanis) who routinely use the service every month. For example in the case of Diabetes Mellitus, it was found that there was a positive relationship between the use of online access to medical records by DM patients with better levels of glycemic control and patient health care management ${ }^{4}$.

Another positive thing is that by being able to access their medical records, patients have a better perception of their health status, get a comprehensive picture of the disease, and 
plan for future management. Patients can also understand and recall what therapies they have received, and the education given by the doctor. Besides, patients can make corrections or clarifications if there is a misunderstanding or error in recording information on medical records ${ }^{5}$. In the future, opening access to medical records for these patients can be considered as a form of innovation and program development, especially in the management of chronic diseases (Prolanis) at KSUI Makara.

\section{INTEGRATED ONLINE SERVICES AND INTERPROFESSIONAL COLLABORATION}

The electronic medical record that has been used by KSUI since January 2019, is a medical record conceptually designed by KSUI. The medical record known as eHealth is deliberately designed to facilitate integrated clinical services and interprofessional collaboration. The use of eHealth starts from reservations, forcing reservation officers to act quickly and appropriately when there is connection disruption or other IT-related disruption. The reservation officer will contact the clinic administration staff to contact the Directorate of Information Systems and Technology UI (DSTI UI) or eHealth according to the problem at hand.

Patients who have registered online will then get an answer that they will be contacted by a doctor, dentist, or psychologist according to their expectations and complaints. At the time promised, the patient will be contacted via WhatsApp messenger and asked for the patient's comfort to choose information media as the next service.

In online consultation services, doctors must be active and creative in conducting anamnesis, as well as virtual physical examinations. The history is carried out in detail, asking all the symptoms experienced by the patient (symptoms of covid: fever, cough, runny nose, sore throat, etc., as well as other additional symptoms), whether he has had contact with a patient who was confirmed positive for Covid-19. Patients with symptoms other than covid symptoms need to be done carefully, related to differences in perceptions between patients and doctors regarding the term pain symptoms.

Besides, it is very necessary to ask the location of the patient, where he lives, and where he works. Not always UI residents who use KSUI online services live around the campus. Especially during the period of distance education (PJJ), it was not uncommon for students to live in other provinces which were very far from Depok. The question of the patient's location is necessary for further management required such as laboratory tests and drug collection. Several times the patient had to be referred to a secondary service but was outside the city, so the patient was asked to come to the nearest hospital of his own choice.

A virtual physical examination can be done by asking the patient to perform a simple examination, by first providing an example through pictures or videos. Patients can be taught how to measure the frequency of breath and pulse if there is an indication of shortness of breath. For chronic patients (Prolanis) who do have equipment such as tensimeters and digital thermometers, we can also encourage them to take measurements regularly and report at the next consultation. Then ask the patient to take pictures of the problematic body parts that are complained of, for example, skin complaints, swelling, redness of the tongue, and so on. Sometimes it is necessary to provide a digital visual example, i.e. an image or video link of an appropriate physical examination. For example, in a patient with complaints of lower right abdominal pain, there is dyspepsia too. Complaints seem to suggest acute appendicitis. We can teach patients to check the laseque test, obturator sign, psoas sign, through pictures. This indeed requires a lot of patience and is indeed quite time-consuming for doctors.

How long does it take for an online consultation? Of course, it depends on the case. On average, experience at KSUI can reach 15-20 minutes, but for those experiencing psychosomatics, it takes a little longer. The challenge for doctors and other health professionals is the ability to communicate well with their patients, and of course, ensure that patients are honest and willing to voluntarily share all their complaints. This is very important so there is no misdiagnosis.

After establishing a diagnosis and providing appropriate management, every doctor and other medical personnel are obliged to fill out an online medical record, and this must be completed on the same day, especially if the patient wants to take prescription drugs at KSUI. The recording system used is SOAP (Subjective-Objective-AssessmentPlanning).

As a service center in primary care, KSUI also follows WONCA (the world association for family doctors and general practitioners) by using the ICPC-2 code (International Classification of Primary Care 2nd edition) in its report. ICPC-2 was used to classify reasons for arrival, occupational diagnosis, and management performed at that time. However, as a report for the Puskesmas which is responsible for the work area (KSUI is in Beji District, Depok City, West Java), eHealth automatically translates ICPC-2 into a code according to ICD-10 (International Classification of Diseases 10th ed). The management plan is recorded not only for medical management plans, but also for non-medical management in the form of education, observation, and horizontal and vertical referrals.

For BPJS patients, but served online, they still use the WhatsApp messenger application. Because we had problems with JKN Mobile BPJS. Referrals to secondary services are also provided online, letters are printed, signed by doctors, then sent to patients via Whatsapp as well. During the online consultation period, OTC or OTC drugs are given to prescribing drugs. As much as possible to avoid the use of antibiotics, it may not be necessary. Pharmacy services during the pandemic are still open on a limited basis 2 times a week and are primarily for healthy patients or Prolanis, who need to regularly take hypertension and diabetes drugs.

During a pandemic, with all health services focused on Covid-19, there is also a growing concern for increasing complications in chronic disease patients. Therefore, KSUI 
improves online nursing services. Nursing activities have been transformed into monitoring follow-up activities for patients. Follow-up activities for patients with ARI symptoms, for 2 weeks after arrival / online consultation. The total number of patients monitored in March was 846 cases. Patient follow-up activities were also performed for patients who were listed as prolanis.

The services of dentists and oral dental therapists were online wherever possible to serve patients by providing online premedication services and follow-up. Psychological counseling services do online counseling services to the same number as non-online ones. Psychology patient clients, almost all of whom are students, benefit from the online service because most of them return to their parents' homes who are not close to campus.

\section{DISCUSSION}

The webinar participants are doctors in primary care. Some of the participants were doctors at the health center, and some were doctors at private clinics. Several questions for the presentation were asked which at the same time increased the insight of other participants. The questions asked and the answers are presented below.

Participants' questions: How to carry out a risk screening process for psychiatric patients who consult online outside the hospital? I am most concerned about the risk of suicidal thoughts. How can you prevent the patient from "acting in self-harm" during the consultation?

Answer: Because KSUI is a primary service, psychological counseling is counseling conducted by clinical psychologists. If necessary, patients will be referred to psychiatrists who have worked with KSUI, namely psychiatrists who are also teaching staff at FKUI / RSCM. Constraints to online psychological counseling: students are not free to consult from home, for fear of being heard by other family members. Unlike the direct consultation in the consultation room. Counselors need to be very careful with students who are already showing symptoms of depression. In cases like this, the counselor makes contact with family members who are carers of the client, asking the family to participate in the management and not leaving the client alone at home.

Participants' questions: If ODP patients are found by online consultation, does the clinic have to coordinate with the local puskesmas? Is it necessary during a pandemic like this to do an initial screening for Covid-19 during the history taking?

Answer: Of course, in pandemic and emergencies, clinics need to coordinate with local health centers. It is also necessary to coordinate with their respective Covid-19 Task Forces, to find out exactly where the correct flow of case reporting is, the aim is to carry out case surveillance. Currently, each region must have developed applications for patient surveillance and monitoring.

For patients with ODP or PDP who are treated at home, online consultation is not only for the patient but also for family members. Online family conferencing with family members is necessary. Families need to obtain information about the pathogenesis of Covid, prevention of transmission, good PHBS and pay attention to patients with worsening symptoms. It is also necessary to provide education on proper independent isolation at home, with separate rooms from other family members.

Participants' questions: What about dishonest patients, don't want to tell them that they have just returned from various cities out there? What is our attitude?

Answer: Right now we have to think the opposite, that all patients tend to be dishonest. The goal is that we prepare the best personal protective equipment (PPE), as safe as possible. Besides that, he always carries out PHBS and makes efforts to increase immunity. With PPE, surgical masks, and gloves, accompanied by routine handwashing habits, how to wear a mask properly (not raising it to the chin), washing practice clothes at the clinic, taking a bath before returning home, and so on.

Participants' questions: Is there currently a legal umbrella that protects online consultation?

Answer: Ministry of Health issued Circular number HK.02.01/MENKES/303/2020 concerning "Implementation of Health Services through Utilization of Information and Communication Technology in the Context of Preventing the Spread of Covid-19" dated April 29, 2020. This Circular, which applies to the internal Ministry of Health, strengthens Permenkes number 20 of 2019 concerning "Implementation of Telemedicine Services Between Health Service Facilities". The Indonesian Medical Council then on April 302020 issued KKI (Perkonsil) Regulation Number 74 of 2020 concerning "Clinical Authority and Medical Practice through Telemedicine during the Pandemic Corona Virus Disease 2019 (Covid-19) in Indonesia" which applies to all practicing doctors and supported by the Indonesian Doctors Association.

\section{CONCLUSION}

Online services are services that can be used as an alternative to health services if they still follow practice principles and are supported by technology and electronic medical records. Besides the need for the desire of health workers to change the way of service, and stick to the principles of patient safety and satisfaction. KSUI has a motto that is continuously maintained by all working health workers, namely "Your Trusted Primary Care".

\section{REFERENCE}

1. Katz SJ, Moyer CA, et al. The emerging role of online communication between patients and their providers. J Gen Intern Med. 2004; 19 (9): 978-983. doi: 10.1111 / j.1525-1497.2004.30432.

2. Mold F, de Lusignan S. Patients' Online Access to Their Primary Care Electronic Health Records and Linked Online Services: Implications for Research and Practice. J Press Med. 2015; 5 (4): 452-469. Published 2015 Dec 4. doi: 10.3390 / jpm5040452.

3. Mold F, de Lusignan S, Sheikh A, et al. Patients' online access to their electronic health records and linked online services: a systematic review in primary care. Br J Gen Pract. 2015; 65 (632): e141-e151. doi: 10.3399 / bjgp15X683941.

4. Mold F, Raleigh M, Alharbi NS, de Lusignan S. The Impact of Patient Online Access to Computerized Medical Records and Services on 
Type 2 Diabetes: Systematic Review. J Med Internet Res. 2018; 20 (7): e235. Published 2018 Jul 6. doi: 10.2196 / jmir.7858.

5. Mold F, Raleigh M, Alharbi NS, de Lusignan S. The Impact of Patient Online Access to Computerized Medical Records and Services on Type 2 Diabetes: Systematic Review. J Med Internet Res. 2018; 20 (7): e235. Published 2018 Jul 6. doi: 10.2196 / jmir.7858. 